\title{
EDUCAÇÃO PARA A COMPREENSÃO INTERNACIONAL: UMA POSSIBILIDADE VIA REDES TELEMÁTICAS? ${ }^{1}$
}

\author{
Mônica Estrázulas* \\ Resumo: Este artigo pretende oferecer subsídeos sobre educação para a compreensão \\ internacional de acordo com a visão de Jean Piaget. Discutimos a operacionalização da idéia no \\ contexto das redes telemáticas. \\ Palavras-chaves: Educação internacional, cooperação, reciprocidade, epistemologia genética, \\ psicologia do desenvolvimento. \\ Keywords: International education, cooperation, reciprocity, genetic epistemology, child \\ developmental, interaction, internet. \\ Abstract: This article intends to offer subsidies for reflections upon cooperation on international \\ education based on Piaget's perspective. We discuss its possibilities in telematic sistems \\ context.
}

\footnotetext{
${ }^{1} \mathrm{O}$ estudo original que inspirou o presente texto integra o projeto de tese desenvolvido pela autora, no Curso de Pós-Graduação em Psicologia do Desenvolvimento/UFRGS, sob a orientação da Profa. Dra. Léa Fagundes.

"Física, Mestre em Psicologia do Desenvolvimento/UFRGS, doutoranda em Psicologia do Desenvolvimento/UFRGS, pesquisadora do Laboratório de Estudos Cognitivos (LEC/UFRGS), docente do Colégio de Aplicação/UFRGS; monicpoa@psico.ufrgs.br ; monicpoa@terra.com.br
} 


\section{Introdução}

A proposta de uma educação para a compreensão internacional consta do documento denominado Plano de Ação ${ }^{\mathrm{i}}$, elaborado por Piaget e oferecido à UNESCO, em 1951. No que consiste? Qual a finalidade e quais os meios empregados ? Como Piaget a justificou? As redes telemáticas poderiam colaborar para viabilizá-la? Para melhor entendermos seu significado, convém inicialmente situá-la e só então examinarmos o problema.

\section{Antecedentes}

A reflexão pedagógica, no início do século $\mathrm{XX}$, coloca em cena uma nova pedagogia, na qual a criança é reconhecida como uma pessoa que constrói conhecimentos, orientada por seus interesses e necessidades na busca da verdade.

A concepção de uma nova escola, a escola ativa, passa a ser defendida com o objetivo de dar suporte à novidade pedagógica e representa a conjugação de esforços necessários à implementação de ações educativas que visam favorecer o desenvolvimento integral do aluno. Esse desenvolvimento o capacita para aprender a partir da atividade suscitada por um interesse seu. A proposta da escola ativa se afasta, portanto, do verbalismo e dos métodos tradicionais de ensino da escola clássica, no qual a autoridade do professor ocupa lugar central e inibe a atividade espontânea da criança.

Na década de 20, o movimento da escola ativa reunia o Instituto JeanJacques Rousseau (IJJR), a recém-criada Liga Internacional para a Educação Nova, diversas instituições educativas e também a Agência Internacional de Educação (BIE). Jean Piaget, que participou intensamente das discussões promovidas pelo movimento, atuou decisivamente através do IJJR e do BIE ${ }^{\mathrm{ii}}$. Nesse último - um reconhecido centro de educação comparada - foi pesquisador e diretor, entre 1929 e 1967. Coube a Piaget, por exemplo, pesquisar e elaborar os argumentos que, até hoje, justificam cientificamente os métodos defendidos pela escola ativa: o self-government e o trabalho em equipe.

\section{Educação para a compreensão international}

A educação para a compreensão internacional consiste na formação de atitudes intelectuais e morais que envolvem toda a personalidade e o comportamento social de um indivíduo (Piaget, 1998, p.243), de tal modo que cada um, sem abandonar o relativo, alcance a objetividade pelo estabelecimento de relações entre pontos de vista, eles mesmos particulares (p.136). A educação para a compreensão internacional deve favorecer a conquista de uma autonomia intelectual (ou espírito de livre pesquisa e necessidade de verificação), autonomia moral ( ou, liberdade e capacidade de avaliação crítica) e a formação de uma atitude social de reciprocidade (ou, um agir segundo a perspectivação de diferentes pontos de vista e o intercâmbio com os dos demais).

\section{Finalidade}


A finalidade da educação para a compreensão internacional é criar em cada pessoa um método de compreensão e reciprocidade (p.135). Com sua formulação simples, essa idéia requer uma atitude profunda e essencial do espírito pois criar um método de compreensão não é outra coisa senão determinar as regras que servem de instrumento para a distinção dos aspectos contingentes da realidade quando da avaliação pessoal das normas e valores que regulam as ações sociais (Freitas, 1997). Piaget entende que essa criação é pessoal, intransferível, mas que só ocorre a partir da relação de cada um com os demais, de onde a importância da condição de reciprocidade.

\section{Meios}

Conhecida a finalidade de uma educação para a compreensão internacional, quais os meios a serem empregados? Como oportunizar a cada pessoa um desenvolvimento moral e intelectual, de modo que cada qual compreenda que a liberdade oriunda da cooperação é autonomia, ou seja, a própria submissão a uma disciplina escolhida e constituida pela colaboração de toda a sua personalidade (Piaget, 1998, p.154)? Que meios oportunizam a educação da liberdade ? A explanação de Piaget, numa conferência proferida em 1944, não deixa margem à dúvida sobre a educação da razão como condição necessária à educação da liberdade :

Não é livre o indivíduo que está submetido à coerção da tradição ou da opinião dominante, que se submete de antemão a qualquer decreto da autoridade social e permanece incapaz de pensar por si mesmo. Tampouco é livre o indivíduo cuja anarquia interior impede-o de pensar e que, dominado por sua imaginação ou por sua fantasia subjetiva, por seus instintos e por sua afetividade, é jogado de um lado para o outro entre todas as tendências contraditórias de seu eu e de seu inconsciente. É livre, em contrapartida, o indivíduo que sabe julgar, e cujo espírito crítico, o sentido da experiência e a necessidade de coerência lógica colocam-se a serviço de uma razão autônoma, comum a todos os indivíduos e independente de toda autoridade exterior (Piaget, 1998, p. 154)

\section{Métodos ativos}

Piaget temia a disseminação de experiências pedagógicas formuladas a partir de um ensino teórico e verbal sobre o ideal da cooperação internacional. Disposto a chamar atenção sobre possíveis disparidades entre finalidade e meios, enfatizou que os meios a empregar deveriam permitir tanto as atividades livres e criativas quanto a colaboração ativa entre as pessoas. E mais, Piaget propõs que a ordem das etapas de uma educação com tal finalidade fosse a inversa da lógica adulta, justamente para ser aproveitável pela criança. A idéia é proceder da ação para a conceituação; das vivências cooperativas ao conceito de cooperação, e assim por diante. Como a proposta piagetiana têm a intenção de fazer corresponder os meios às finalidades sugeriu o emprego de dois métodos ativos: o self-government e o trabalho em equipe. Esses métodos se aplicam à vida em geral: das crianças entre si, dos adultos e 
crianças, pais e filhos, mestres e alunos. As considerações a seguir, no entanto, priorizam os dois métodos relativamente à vida na escola.

O self-government é um procedimento de educação social que tende, como todos os outros, o ensinar os indivíduos a sair de seu egocentrismo para colaborarem entre si e a se submeter as regras comuns ( Piaget, 1998, p. 119). Consiste no compartilhamento das decisões e de parcela da responsabilidade da disciplina escolar, entre professores e alunos, numa amplitude que varia das simples atribuições de zelo até a organização autônoma de atividades de classe e extra-escolares.

O trabalho em equipe é um procedimento de educação que oportuniza um espírito pessoal de experimentação se desenvolver livremente, numa atmosfera de controle mútuo e reciprocidade. Consiste na atividade construtiva demandada por invenções e verificações reguladas por normas da objetividade e da coerência lógica, levada a efeito por alunos e professores.

O fato fundamental a ser consignado pelos métodos ativos do selfgovernment e do trabalho em equipe, talvez possa ser colocado nos seguintes termos: superação progressiva do egocentrismo intelectual e moral, autonomia para enfrentar as coerções sociais e coordenação dos pontos de vista numa perspectiva de reciprocidade.

\section{Justificativa}

Passemos finalmente, aos argumentos que justificam a necessidade de uma educação para a compreensão internacional. Iniciemos pelo registro de um recente acontecimento e, logo em seguida, às reflexões originais de Piaget.

$\mathrm{O}$ discurso de abertura do Forum Internacional For a Culture of Peace and Diallogue among Civilizations in The Third Millenium, proferido por Federico Mayor, Diretor-Geral da UNESCO, na cidade de Moscou, em 1999, destacou a importância do encontro para os ali presentes e para as futuras gerações. Soto Mayor lembrou as palavras iniciais da Carta das Nações Unidas, assinada em 1945, e sublinhou: não se referem aos governos (We the governments) mas aos povos (We the people). Isso significa que embora os membros da ONU possam ser EstadosNação, grandes ou pequenas, seu dever é colocar os povos em primeiro lugar. Soto Mayor afirmou que a educação é o mais importante e decisivo elemento no processo de paz construída porque, segundo ele, o caminho para realizarmos a transição da cultura da guerra para a cultura da paz e do diálogo exige a modificação de valores, atitudes e comportamentos do passado.

Setenta anos antes do discurso de Soto Mayor, numa conferência ${ }^{\text {iii }}$ para educadores em Genebra, Piaget (1998) apresentara uma reflexão que, infelizmente, permanece válida:

Nunca esteve tão claro quanto hoje que as flutuações materiais das finanças ou da indústria dependem, em última instância, de fatores morais. Nunca se viu a política, sob seu aspecto realista ou até jurídico, manifestar de forma mais simples a miséria afetiva e intelectual do homem, e nunca os ideais nacionais traduziram com mais inabilidade a falta de universalidade de que ainda sofre a razão humana ( p.80). 
Hoje, iniciado novo século e milênio, observado o espetáculo do mundo atual, parece lícito afirmar que, dificilmente a humanidade será capaz de se transformar sem a intervenção de propostas educativas que consigam penetrar em profundidade, e não em extensão o espírito das novas gerações, dos diferentes povos, em todos os lugares (Piaget, 1998, p.79). Parece razoável, também, afirmarmos que a interdependência dos problemas implica a das soluções e que, ambas, não podem ignorar a coordenação dos pontos de vista, quer esses representem pessoas, povos ou Estados-Nação. A escala atual do problema (cultura da guerra), ou de sua solução (cultura da paz e do diálogo), é simultaneamente individual e coletiva, pessoal e planetária.

Como Diretor do BIE, Piaget argumentava que, tanto o fato das mudanças ocorrerem cada vez mais rápido, como também a inexistência de dispositivos de coordenação entre diferentes perspectivas numa escala mundial, em parte, justificavam o atraso da humanidade diante da necessidade de um agir na perspectiva da cooperação internacional.

Se a riqueza da humanidade está justamente relacionada à diversidade de suas experiências, não podemos prescindir da coordenação entre as perspectivas distintas para a constituição da verdade (Piaget, 1998). Sendo assim, quando se pensa numa proposta de educação internacional, é necessário faze-lo considerando-a como um esforço de compreensão entre indivíduos, a partir das oportunidades de conviver e produzir conhecimento cooperativamente. Nesse sentido, é necessário levar em conta, além dos métodos ativos a empregar, os atuais dispositivos técnicos (como as redes telemáticas) para promover a coordenação das próprias atividades. Tal coordenação deve ser tomada, igualmente, como condição a ser satisfeita pela educação para a compreensão internacional.

A idéia de cooperação internacional repousa sobre o aprendizado das noções de solidariedade e justiça. Esse aprendizado, entretanto, só acontecerá verdadeiramente se a solidariedade e a justiça forem vivenciadas antes de se tornarem objeto de reflexão. A razão disso é que tal aprendizado decorre de uma lógica (lógica das relações) que somente se desenvolve a partir de descentrações provocadas por relações interindividuais, caracterizadas pela livre discussão e pesquisa objetiva. O ideal da cooperação internacional adquire significação para a criança, portanto, se resultar de uma série progressiva de cooperações sociais, morais e intelectuais, vividas em todos os aspectos da vida escolar e extra escolar (p.88).

Quais os meios para conduzir uma proposta de educação para a compreensão internacional sem reduzi-la à verbalização das noções de solidariedade e justiça, o que impediria alcançar a finalidade pretendida, ou seja, a prática da cooperação moral e intelectual ? Como coordenar as atividades nas diferentes escalas: familiar, escolar, comunitária, regional, nacional, internacional?

Guardadas as situações nas quais o egocentrismo intelectual e moral é ainda constitucional, como nos bebês e crianças pequenas, necessitamos permanentemente vencê-lo para dar lugar à vida em relação, em todos os níveis, desde o campo científico até o interpessoal. Como alcançar a independência de pensar com liberdade, com autonomia, sem nos deixar escravizar pelas tradições e coerções sociais num plano que não seja apenas o das decisões aparentemente domésticas? Como compreender e ser solidário com quem sequer conhecemos, tal como um cidadão de outro país e de uma outra cultura? Como conseguir pensar e agir com autonomia em questões sobre paz internacional, por exemplo? Como o cidadão comum pode ter 
acesso e influir no conjunto das discussões mundiais, antes mesmo que decisões sejam tomadas?

Entendemos que a conservação de um pensamento próprio e a manutenção de nossa perspectiva é, como afirmou Piaget, algo inalienável, que define o que nos é particular, nossa ligação com o real. Portanto, não se trata de negar o próprio ponto de vista, mas de conseguirmos perspectivá-lo. Daí que a idéia de reciprocidade, ou seja, a oportunidade para que todos situem suas idéias em relação às dos outros, garante o aspecto universal da proposta educativa.

Se somente é possível pensar a educação para a compreensão internacional a partir da superação do egocentrismo mediante um agir com autonomia e reciprocidade, quando e como os indivíduos teriam oportunidade para desenvolvê-las? Piaget concluiu que seria justamente a partir da infância pois ao observar as crianças, nas situações em que conseguem agir sem a intervenção de adultos, na família ou na escola, as mesmas dão mostras de uma socialização que evidencia a presença de espírito crítico tanto quanto a ocorrência de questionamentos que se opõem à obediência pura e simples. A consciência autônoma se desenvolve, se não for anulada a partir do exterior. Entretanto, é preciso indagar sobre o que colabora para impedir que a humanidade se desenvolva moral e intelectualmente, se esta parece ser uma tendência natural do ser humano? A resposta recai sobre a educação que recebemos, exatamente porque ela atua de forma coercitiva sobre as crianças, negando-lhes oportunidades de construirem um instrumento psicológico fundado na reciprocidade e na cooperação. Nesse caso, se preservássemos a condição inata de toda a deformação provocada pela coerção na família ou na escola, esta seria suficiente para fazer alcançar a socialização pretendida pela educação que visa à compreensão internacional? Absolutamente não, porque é necessário que a criança descentre do egocentrismo inconsciente, assimile aos poucos os valores e regras da cultura e se estruture, se situe no mundo. Tal afirmação da criança se dá aos poucos, em função dos confrontos e objeções exteriores, tanto quanto da aprovação e solidariedade dos demais. A utilização da lógica das relações vai se tornar possível somente em função da reciprocidade vivida no grupo, mas deve, necessariamente, se generalizar e ultrapassar os limites do conhecido, do previsto e do alvo de nossa estima. É nesse sentido, o da vida em relação, que o advento das redes telemáticas assume um papel preponderante junto à proposta de educação para a compreensão internacional.

\section{Educação para a compreensão internacional e redes telemáticas}

As redes telemáticas poderiam colaborar para viabilizar o desafio proposto, qual seja, a promoção de ações criativas de amplitude mundial voltadas ao aprendizado da solidariedade e da justiça, decisivo para o processo de paz que hoje demanda esforços, reune organizações, povos e culturas ?

Em nosso entendimento, sim, desde que sejam suporte para interações entre pessoas livremente associadas em torno de oportunidades ou interesses que as levem a tentar coordenar ações, segundo critérios de reciprocidade, autonomia moral e intelectual.

Dado que a escala do desafio é planetária e a rede telemática se expande num espaço de comunicação ampliado por meta-interfaces (Randall, 1995) e serviços como listas de discussão, chats, fóruns, blogs, icqs,...além de integrar mídias de massa em 
formato digital (TVs, rádios, jornais, ...), parece imprescindível aproveitarmos o potencial agregador, associativo ou comunitário do computador coletivo $(C C)$, o ciberespaço (Lemos, 2002). A interconexão viabilizada pelas redes telemáticas concorre, portanto, para potencializar práticas sociais e ações voltadas à educação para a cooperação, o que em última análise constitui estratégia que converge para o alcance da paz mundial.

Tendo em vista a finalidade de uma educação para a compreensão internacional ( criar em cada pessoa um método de compreensão e reciprocidade) e os meios a empregar ( self-government e trabalho em equipe), entendemos como desejável a realização de ações educativas continuadas, em rede, na escola e/ou fora da escola, que combinem interações presenciais e a distância, entre crianças, jovens e adultos de diferentes comunidades ou culturas.

\section{Um design possível}

Nesse caso, um exemplo de design possível é obtido quando uma rede de interações a distância (lista de discussão) conecta todos os seus elementos constituintes, os quais, por sua vez, são redes de outras redes de interações que se conjugam sucessivamente, umas às outras, pela presença de elementos constituíntes em comum , como ocorre, por exemplo, quando os alunos e professores participam de uma mesma discussão (forum, chat, troca de mensagens) ou de um mesmo trabalho desenvolvido em equipe (projeto de aprendizagem), ou de um mesmo grupo orientado pelo(s) mesmo(s) professor/professores, ou ainda, de grupos formados por participantes de uma mesma escola, cidade, região, país, e assim por diante.

Afirmamos então que, a rigor, se uma rede:

- é um sistema aberto cujos elementos constituintes são necessariamente : pessoas, grupos ou outras redes (elementos) e as interações que estabelecem entre si (ligações);

- possui elementos que compartilham espaços (meio), geográficos ( nas interações presenciais) ou virtuais (nas interações a distância), em modo síncrono ou assíncrono;

- aglutina os elementos em torno de motivos, razões e afinidades, uma vez que só existe no tecer junto ( complexus);

- viabiliza trocas em âmbito local e global, condição à formação de comunidades que se desafiam à compreensão e à reciprocidade, posto que não possuem necessariamente uma mesma herança histórica e cultural,

podemos empregá-la para os propósitos da educação para a compreensão internacional pois a sua constituição e manutenção só se viabiliza quando os integrantes da rede ativamente procuram:

- conquistar as condições de colaboração recíproca e também submeter-se às regras comuns, combinadas entre si, como por exemplo, quando da divisão ou compartilhamento de responsabilidades relacionadas ao bom andamento dos projetos de aprendizagem, `as providências relativas à manutenção da lista de discussão ou às regras convivência do grupo;

- regular suas invenções e verificações para, segundo normas da objetividade e procedimentos da coerência lógica, validar os resultados obtidos a partir da livre 
experimentação das hipóteses, sejam elas diretamente relacionadas ao uso das tecnologias disponíveis ou fruto das tentativas de perspectivação dos pontos de vista.

\section{Educação para a compreensão internacional : uma possibilidade via redes telemáticas}

A proposta de educação para a compreensão internacional de Jean Piaget inspirou um estudo qualitativo, em fase de conclusão, realizado pela autora deste artigo, no qual jovens e educadores do Brasil (Porto Alegre, Santa Maria-RS, ItararéSP, São Paulo-SP, Belém-PA), Uruguai, Costa Rica, Portugal, e Japão, integraram uma rede de interações presenciais e a distância ( Projeto Rede JovemPaz). Os resultados evidenciam a aprendizagem das noções de solidariedade e justiça a partir do desenvolvimento da lógica das relações. 


\section{Referências Bibliográficas}

PIAGET, J. Sobre Pedagogia. São Paulo : Casa do Psicólogo, 1998.

FREITAS, L. A moral na obra de Jean Piaget: um projeto inacabado. São Paulo, 1997. Tese de Doutorado.

UNESCO. Federico Mayor . Base de dados UNESDOC , documento DG/99/15 disponível em

< http://unesdoc.unesco.org/ulis/ > acessado em 22 fev. 2003

RANDALL, N. The world Wide WEB: Interfaces on the internet. In : J. December, N. Randall\& W. Tatters (Orgs.)1995, Discover World Wide Web. Indianópolis: Sams.net Publishing

LEMOS, A . Aspectos da cibercultura: vida social nas redes telemáticas. In: Crítica das práticas midiáticas: da sociedade de massa às ciberculturas. (Org.) José Luiz Adair Prado - São Paulo: Hacker Editores: 2002.

' O Plano de Ação constitui manuscrito inédito de Piaget, disponível como Anexo, em Piaget, J. Sobre Pedagogia São Paulo : Casa do Psicólogo, 1998.

ii O BIE mantém página atualizada em < http://www.ibe.unesco.org/About|BE/hiss.htm >

iii A conferência "Comment faire connaitre la Société des nations et développer l'ésprit de coopération internationale" integrou o quarto curso para profissionais do ensino e consta do relatório de conferências proferidas de 3 a 8 de agosto de 1931, em Piaget, J. Sobre Pedagogia - São Paulo : Casa do Psicólogo, 1998. 